\title{
Referentiality and Incompletive Reading in Mandarin
}

\author{
Anqi Zhang*
}

\begin{abstract}
As an exception to Krifka's (1989) famous generalization that a quantized incremental theme always induces an event-homomorphic completive reading, Singh $(1991,1998)$ observes that in Hindi only the quantized mass noun phrases as the incremental theme entails a completive reading, but unexpectedly quantized count nouns phrases can have an incompletive reading. She proposes that count nouns can introduce a partial thematic relation, whereas mass nouns introduce a total thematic relation. With new data in Mandarin, instead of the mass/count distinction, I argue that referentiality is the crucial factor because the non-culmination readings are only felicitous with the referential objects for consumption verbs in Mandarin.
\end{abstract}

Keywords. referentiality; event completion; consumption verbs; incompletive read-ing; Mandarin

1. Introduction. Based on a corpus analysis of Mandarin, Koenig and Chief (2007) show that accomplishment predicates with a quantized incremental theme with the form [Num $+\mathrm{CL}+\mathrm{N}]$ can have a non-culminating reading (contra Soh and Kuo 2005). However, if we replace [Num+ $\mathrm{Cl}$ ] with [Num+ Measure], the non-culminating reading disappears as in (1). This looks similar to Singh's $(1991,1998)$ description of Hindi (though her examples involve a contrast between mass and count nouns), which she analyzes in terms of two gradual patient thematic relations that differ in completion entailment in a mereological analysis of telicity (cf. Krifka 1989).

$$
\begin{aligned}
& \text { wo chi le san ge/*bang pingguo, mei chi wan. } \\
& \text { I eat PFV three } \mathrm{CL} / *^{*} \text { pound apple, not eat finish. } \\
& \text { 'I ate three apples/*pounds of apples, but did not finish.' }
\end{aligned}
$$

In this paper, I argue instead that the crucial factor is the referentiality of the incremental theme. My arguments are based on data like (2) and (3), which show that when [Num+ Measure] NP is marked with a demonstrative or occupies the preverbal topic position which is reserved for referential NPs (cf. C. N. Li and Thompson 1989; Paul 2002), the incompletive reading comes back.

$$
\begin{aligned}
& \text { wo chi le na san bang pingguo, mei chi wan. } \\
& \text { I eat PFV that three pound apple, not eat finish. } \\
& \text { 'I ate those three pounds of apples, but did not finish.' }
\end{aligned}
$$

$$
\begin{array}{llllll}
\text { wo san bang pingguo dique chi le , mei chi } & \text { wan. } \\
\text { I three pound apple indeed eat PFV, not eat finish. } \\
\text { 'I indeed ate (specific) three pounds of apples, but did not finish.' }
\end{array}
$$

In my new analysis, I argue that incompletive readings can arise whenever the object NP can have a referential reading, because in Mandarin verbs of consumption and their objects are in a partial thematic relation. However, when the NP is non-referential, i.e. quantificational, it serves

\footnotetext{
* I would like to thank my dissertation committee Chris Kennedy, Ming Xiang, and Itamar Francez for their insightful feedback and discussions on this project. I would like to also thank the LSA participants who gave me valuable feedback and suggestions during the conference. All errors are on my own.

Author: Anqi Zhang, University of the Chicago (anqi@uchicago.edu).
} 
as an event measurement function that measures out the event homomorphically against the amount of the NP consumed in the event, and consequently in this scenario only the completive reading is possible.

2. Background. In event semantics, it is well known that telicity of a predicate can vary depending on whether the direct object NP is quantized or not (Dowty 1979; Bach 1986; Krifka 1989, 1998; among others). As shown in (4), when the direct object 'apples' is not quantized as a bare plural noun, the predicate 'eat apples' is an activity, as the predicate can co-occur with a for-phrase rather than an in-phrase, two tests for activity and accomplishment predicates respectively. In contrast, as shown in (4), when the direct object is quantized with the numeral 'three' in front, the predicate 'eat three apples' becomes an accomplishment and now co-occurs felicitously with the in-phrase rather than the for-phrase.

a. I ate apples for two hours/\#in two hours.

b. I ate three apples \#for two hours/in two hours.

Based on this pattern, Krifka (1989) proposes that these consumption verbs have a gradual patient relation because they describe events that are homomorphically mapped onto their direct objects. When the direct object NP is quantized by having a numeral or a definite or demonstrative determiner, the event is also quantized so that the predicate is an accomplishment (cf. Vendler 1957). Likewise, when the NP is not quantized as a bare plural or a mass noun, the event is not quantized either, so that the predicate is an activity. Because of this homomorphic mapping relation, the event is measured out by the direct object, meaning that the event is completed at the same time as the direct object is entirely consumed. For example, in the case of 'eat three apples', the event progresses at the same rate as the three apples are being consumed and ends at the exact moment when the last bit of apple is eaten.

Krifka's influential mereological analysis predicts that all such types of accomplishments with a quantized direct object should have a completive reading in the perfective, because the accomplishment event is homomorphic to its direct object and the perfective aspect asserts the event is complete. Therefore, 'I ate three apples' should entail that the three apples have been entirely eaten, because the completion of the event occurs at the same time as the last bit of the three apples is finished. Indeed, it does entail that three apples were completely eaten in English. However, for many other languages, it has been observed that this is not always the case. For example, Singh $(1991,1998)$ observes for Hindi, predicates such as 'eat my cake' can have a incompletive reading that the cake was only partially eaten as in (5).

$$
\begin{aligned}
& \text { Hindi (Singh 1998: 172) } \\
& \text { mãẽ ne aaj apnaa kek khaayaa aur baakii kal khaaũũgaa } \\
& \text { I ERG today mine cake eat-PERF tomorrow remaining tomorrow eat-FUT } \\
& \text { 'I ate my cake today and I will eat the remaining part tomorrow.' }
\end{aligned}
$$

To account for the Hindi data, Singh $(1991,1998)$ proposes that there are two different thematic relationships: total or partial, depending on whether the direct object is a mass noun or a count noun. Although the Chinese data that I discuss in this paper are very similar to the Hindi data, there are differences such as those Mandarin examples in (2) and (3), where clearly referentiality rather than the mass/count distinction is responsible for the incompletive reading. In the remaining of the background section, I first discuss in some details Singh's analysis and why it cannot be fully extended to the Chinese data, and then I discuss some of the previous studies on 
incompletive readings in Mandarin and why these accounts cannot fully capture the whole picture either.

2.1. SiNGH'S ANALYSIS OF HINDI. Singh $(1991,1998)$ crucially observes that the incompletive reading can only arise when the direct object is a count noun, but never when it is a mass noun. Compare the following example (6) with (5). When the direct object is a mass noun 'beer' instead in (6), it is infelicitous to assert the event is not completed with the sentence continuation 'but did not drink all of it.

$$
\begin{aligned}
& \text { Hindi (Singh 1998: 186) } \\
& \text { us ne do gilaas biiyar pii (*par puurii nahĩ pii) } \\
& \text { he ERG two glasses beer drink-PERF ( but entire NEG drink-PERF) } \\
& \text { 'He drank two glasses of beer (* but did not drink all of it).' }
\end{aligned}
$$

Singh argues that this contrast can be explained if there are actually two separate thematic relations in the material domain for the mass nouns, and in the individual domain for the count nouns. Whereas in the material domain the thematic relation is a total, in the individual domain the relation is partial. As shown in (7a), the thematic relation for the material domain denotes a total relation in the sense that every subpart of the object NP participates in a subevent, and that each subevent has a subpart of the object NP involved. In contrast, the thematic relation for the individual domain as in (7b) only requires that for each of the atomic parts of the object NP, there is a material subpart of that atomic part that participates in the event and that each subevent has a material subpart involved. Because of how the thematic relations differ for these two domains, only count nouns can have incompletive reading in Hindi.

(Singh 1998: 188-187)

$$
\begin{array}{ll}
\text { a. } & \theta_{m}(e, x) \leftrightarrow \forall x^{\prime}\left[x^{\prime} \sqsubseteq x \rightarrow \exists e^{\prime}\left[e^{\prime} \sqsubseteq e \wedge \theta_{m}\left(e^{\prime}, x^{\prime}\right)\right]\right] \wedge \exists e^{\prime}\left[e ^ { \prime } \sqsubseteq e \rightarrow \exists x ^ { \prime } \left[x^{\prime} \sqsubseteq\right.\right. \\
& \left.\left.x \wedge \theta_{m}\left(e^{\prime}, x^{\prime}\right)\right]\right] \\
\text { b. } & \theta_{i}(e, x) \leftrightarrow \forall x^{\prime}\left[x^{\prime} \sqsubseteq A x \rightarrow \exists x^{\prime \prime}, e^{\prime}\left[x^{\prime \prime} \sqsubseteq h\left(x^{\prime}\right) \wedge e^{\prime} \sqsubseteq e \wedge \theta_{m}\left(e^{\prime}, x^{\prime \prime}\right)\right]\right] \wedge \forall e^{\prime}\left[e^{\prime} \sqsubseteq\right. \\
& \left.e \rightarrow \exists x^{\prime}\left[x^{\prime} \sqsubseteq h(x) \wedge \theta_{m}\left(e^{\prime}, x^{\prime}\right)\right]\right]
\end{array}
$$

Singh's account does indeed successfully capture the pattern of the Hindi data, but this account is still not sufficient for several reasons. First, proposing two different thematic relations for the same verb seems to be somewhat stipulative without really explaining why only the individual domain can have the partial thematic relation. Second, this account cannot be fully extended to the Mandarin data, because mass nouns in Mandarin can also have a incompletive reading as long as they are made referential. Under Singh's current analysis, all mass nouns would be predicted to have only completive readings. Therefore, in light of the new data from Mandarin, it is necessary to formulate a new analysis that can take referentiality into account.

2.2. PRevious AnAlyses IN MANDARIN. Just like in Hindi, Mandarin verbs of consumption and of creation have also been observed to allow incompletive readings in some situations in previous studies (Smith 1997; Soh and Kuo 2005; Koenig and Chief 2007; among others). However, these previous analyses sometimes disagree on when exactly such readings are allowed. For example, on the one hand, according to Soh and Kuo (2005) as shown in (8), for consumption verbs in Mandarin, it is felicitous to assert that the event is incomplete when the object NP has a demonstrative but not when it has a numeral. Koenig and Chief (2007), on the other hand, show with an attested example from Google that the incompletive reading can be present even for NPs with a numeral as in (9). It seems that native speakers more or less agree that a definite NP with a demonstrative can indeed have a incompletive reading in some circumstances, they differ to 
various degrees with respect to whether they accept the incompletive readings for the indefinite quantized NP.

Mandarin (adapted from Soh and Kuo 2005: 204)

Ta chi-le \#liang-ge dangao/ na-ge dangao, keshi mei chi-wan.

He eat-PERF two-CL cake/ that-CL cake but not eat-finish

'He ate two cakes/that cake, but he did not finish eating them/it.'

$$
\begin{aligned}
& \text { Mandarin (Koenig and Chief 2007: 247) } \\
& \text { Wo (...) chi-le liang-chuan dakao, dan mei chi-wan Google } \\
& \text { I eat-PERF two-CL kabob, but not eat-finish } \\
& \text { 'I ate two kabobs, but didn't finish eating them. (lit.)' }
\end{aligned}
$$

It is probably not all that surprising that different speakers vary considerably in their acceptance of such sentences as felicitous given that most of these sentences by default are considered to describe completed events through pragmatic reasoning, when uttered on their own without the cancelation of the completion implicature. Some of these incompletive readings are admittedly quite hard to get without the suitable contexts and some efforts on the listener's part to think more carefully about the data.

Nevertheless, one important point that the previous studies in Mandarin do agree on is that it is much easier to get an incompletive reading for a definite NP than an indefinite quantized NP. This suggests that actually referentiality plays a very important role in determining whether an incompletive reading is felicitous for Mandarin consumption and creation verbs. And yet, none of these aforementioned studies have investigated extensively how referentiality of the direct object NP affects the event semantic composition, probably since referentiality is not considered as crucial a factor in Krifka's $(1989,1998)$ canonical account, in which he groups the definite NPs together with the quantized NPs both as bounded NPs. And according to this canonical theory, neither should have an incompletive reading because of the event homomorphism.

Because very few of the previous studies in Mandarin have considered the full range of data, these analyses with incomplete sets of data cannot truly account for the full picture in Mandarin. To fill in this gap, in the next section, I present what I consider to be more or less a fuller set of data necessary to tease apart the effects of mass/count distinctions and referentiality. I show that actually the incompletive readings can be ultimately accounted by the factor of referentiality alone, and the mass/count distinction is only indirectly relevant because of their inherent difference in their referentiality.

3. New Data. In this section, I argue that referentiality rather than the mass/count distinction of the object NP determines whether a incompletive reading can arise. Crucially, I show that regardless of the mass/count distinction of the object NP, whenever the object NP can be interpreted as referential, an incompletive reading may arise. This situation arises either when the direct object as an indefinite NP has a measure word or a classifier that can introduce referential atomic references, or when the direct object is a definite NP which is made referential by context.

3.1. INDEFINITE NPS. First, let's consider the case of indefinite NPs as the direct objects in the canonical post-verbal direct object position. When the object NP is introduced in the post-verbal position rather than the internal topic position, the NP usually has an indefinite reading in Mandarin (cf. C. N. Li and Thompson 1989; Paul 2002). When we consider various combinations of numeral-classifier phrases here, individuating or non-individuating classifiers with mass or count 
nouns (cf. Rothstein 2009, 2010), we see that regardless of the count/mass distinction of the noun head, the incompletive reading is only felicitous when the classifier or the measure word is individuating, i.e. describing referential atomic entities. As shown in (10) and (11), it does not matter whether the head noun is a count noun 'apple' or a mass noun 'water', as long as the classifier or the measure word is individuating such as an individuating classifier ge for countable nouns in (10a) or a concrete measure word wan 'bowl'in (10b) in Mandarin, then the sentence can be conjoined with a clause that cancels the completion implicature. In contrast, as shown in (11), if abstract measure words such as bang 'pound' or sheng 'liter' are used instead, which do not introduce referential atomic entities but only introduce an abstract amount, then the sentences must entail that all of the amount has been consumed and consequently an incompletive reading is not felicitous.
a. wo chi-le san-ge pingguo, mei chi-wan.
I eat-PERF three-CL apple, not eat-finish.
'I ate (some part of) three apples, but didn't finish.'
b. wo he-le san-wan shui, mei he-wan.
I drink-PERF three-bowl water, not drink-finish.
'I drank (some part of) three bowls of water, but didn't finish.'
a. \# wo chi-le san-bang pingguo, mei chi-wan.
I eat-PERF three-pound apple, not eat-finish.
Intended 'I ate (some part of) three pounds of apples, but didn't finish.'
$\begin{array}{ccll}\text { b. \# wo he-le } & \text { san-sheng shui, mei he-wan. } \\ \text { I drink-PERF three-liter water, not drink-finish. }\end{array}$
'I drank (some part of) three liters of water, but didn't finish.'

In comparison with the Hindi data in Singh's $(1991,1998)$ paper, the Mandarin data is similar in such a way that for the incompletive reading, each of the atomic parts of the NP must be at least partly consumed. It would be infelicitous to utter sentences in (10), if only two out of the three apples or three bowls of water were partly consumed. However, unlike the Hindi data, even the mass noun such as shui 'water' can be compatible with a incompletive reading, as long as the measure word is a concrete measure word 'bowl' that can introduce atomic references.

To understand why the non-completeness reading correlates with the individuating functions of the classifier or the measure word, it is necessarily to take a closer look at the relations between referentiality and the semantic derivation of the Mandarin NP with respect to the information structure. In the canonical object position, usually the NP is introduced as a piece of new information so that the object NP cannot be interpreted referentially as a specific entity which has been already mentioned or assumed in the common ground. The only way for an indefinite NP to be referential is by having atomic parts, which are individuated in a sense that they are delineated and independent from each other. In the semantic structure of Mandarin NP, because the NP requires a classifier or a measure word between the numeral and the noun, the classifier or the measure word themselves are commonly analyzed to be responsible for introducing the atomic structure if such an atomic structure is possible for the interpretation (cf. Chierchia 1998). For these reasons, indefinite NPs can only have referential readings when the classifier or the measure word is individuating.

3.2. DEFINITE NPS. While previous studies have discussed a great amount about indefinite NPs as the direct object, surprisingly little has been said about definite NPs in event semantics. Especially, it is not yet clear what would happen if different combinations of classifiers or measure 
words with mass or count nouns were made definite. In Krifka's $(1989,1998)$ canonical theories, because definite NPs are bounded, as the direct object they would simply induce a event-homomorphic completive reading. And yet, many subsequent studies observe that definite NPs actually can have incompletive readings occasionally (cf. Soh and Kuo 2005; Rothstein 2008), without going further into details about the different completion entailment patterns of different types of definite NPs. To fill in this gap, I present the relevant data below in this section.

Let's consider the following examples. If we add a demonstrate $n a$ 'that' in front of the numeral-classifier phrase to examples (10) and (11) to produce (12) and (13) below, then actually regardless of the mass/count distinction or the type of the classifier or measure word, all example sentences below are felicitous under the right contexts, even for the NPs with non-individuating abstract measure words. For example, imagine a scenario where a mother and a daughter are talking about some amount of apples or water that a relative brought to them earlier. If the mother asks 'did you eat those three pounds of apples/drink those three liters of water', then the daughter can felicitously refer to those three pounds of apples or three liters of water as a definite referential entity as a group, and answer with the sentences in (12) and (13) to express that she did eat some part of those three pounds of apples or those three liters of water.
a. wo chi-le na san-ge pingguo, mei chi-wan.
I eat-PERF that three-CL apple, not eat-finish.
'I ate (some part of) those three apples, but didn't finish.'
b. wo he-le na san-wan shui, mei he-wan.
I drink-PERF that three-bowl water, not drink-finish.
'I drank (some part of) those three bowls of water, but didn't finish.'
a. wo chi-le na san-bang pingguo, mei chi-wan.
I eat-PERF that three-pound apple, not eat-finish.
'I ate (some part of) those three pounds of apples, but didn't finish.'
b. wo he-le na san-sheng shui, mei he-wan.
I drink-PERF that three-liter water, not drink-finish.
'I drank (some part of) those three liters of water, but didn't finish.'

In (12), now that the numeral-classifier phrases with the individuating classifiers or measure words are made definite by the demonstrative $n a$ 'that', there are actually two possible ways to fulfill the truth conditions for the sentences to be true. Unlike their indefinite counterparts, where each atomic part has to be eaten or drunk at least partially for 'I ate three apples' and 'I drank three bowls of water' to be true in Mandarin, the definite NPs only requires that some part of the specific three apples or three bowls of water to be partly eaten or drunk. For example, if the speaker partook a part of one out of those three apples or a small portion of one bowls out of the three bowls of water, the sentences in (12) are considered true.

$$
\begin{aligned}
& \text { wo san-bang } \quad \begin{array}{l}
\text { pingguo dique chi-le, dan mei } \\
\text { I three- POUND }
\end{array} \text { apple chi-wan. } \\
& \text { 'I ate (the) three pounds of apples indeed, but did not finish' }
\end{aligned}
$$

Similarly, as shown in (14), preposing the direct object NP to the internal object position also makes the incompletive reading felicitous because the internal object position is reserved for referential NPs. In (14), it is understood san bang pingguo 'three pounds of apples' is referring to a definite three pounds of apples that have been mentioned or assumed in the background. And 
with the definite reading, it is felicitous to assert to have partially eaten the three pounds of apples in Mandarin.

Why does definiteness license incompletive readings and how does the pattern with the definite NP relate to the pattern with the indefinite NPs in the previous subsection? Again, just like the individuation function of the classifier or the measure word, definiteness also relates to referentiality because an NP can be made referential by being definite. According to Link (1983) and Landman (1989a, 1989b), definite plurals can form a group atom, a referential entity that groups the plural definites into a single entity, because singling out this set of plural entities in the context sets them apart from the rest of their kind. Likewise, I argue that making an amount of mass or count nouns in (13) definite can also create an atomic reference, because this specific amount of stuff is now contextually salient and made separate from the rest of its kind. In order words, besides that individuating classifier or measure words can introduce inherent atomic references, making a group or an amount salient in the context can also form derived atomic references.

Summarizing the patterns from both the indefinite NPs and the definite NPs, one clear pattern emerges: whenever the NP can have a referential interpretation, either through inherent atomic references or derived atomic references in the context, an incompletive reading can arise in Mandarin. Unlike Singh's $(1991,1998)$ analysis of the Hindi data, for Mandarin the mass/count distinction of the noun is only indirectly relevant by the classifier or measure words that they take. And ultimately, it is referentiality that explains how the individuating function of the classifier or the measure word accounts for the incompletive reading for the indefinites.

Therefore, through the discussion of the data in this section, we can clearly see that referentiality is the key factor that explains for when a incompletive reading is felicitous for the consumption verbs in Mandarin.

4. Analysis. From the previous section, it is clear that incompletive reading is possible whenever the direct object NP can be interpreted as referential. Based on this new insight, I argue that consumption verbs in Chinese always have a partial thematic relation with its referential direct object. In other words, 'ate X' means that at least some part of the referential NP is eaten. However, when the NP cannot be interpreted referentially, it is interpreted quantificationally as an event measurement function instead, which always entails a completive reading.

4.1. SEMANTIC COMPOSITION OF THE REFERENTIAL NP. When the direct object has a referential reading or several possible referential readings, the referential entities are each in a partial thematic relationship with the consumption verb. In other words, as long as each atomic part of the NP is taken in part, the sentence will be semantically true. Notice, however, the relevant atomic parts made available by the sentences are not necessarily the actual smallest atomic parts of the reference in the real world, because in the case of definite plurals or definite mass nouns, group atoms can contain actual smaller atoms within, but these smaller atoms are not relevant for the group atom reading, because as long as the group atom is partially consumed, it does not matter whether each of the smaller atoms is consumed. For example, for 'I ate those three apples' in Mandarin to be true, when the three apples are considered to be one unit, it is sufficient that even just one of the three apples has been eaten partially and not necessarily for each of the three to have been eaten.

To model this partial thematic relationship, I adapt and modify my own version of the partitive operator from Kennedy (2012) in (15), which combines the partitive function and the patient role introduction function in one. Because the referentiality and quantificational NPs configure the syntactic-semantic composition differently, I assume that arguments are introduced externally in the syntax (cf. Kratzer 1996) and propose the following structure in (16). 
Adapted and modified from (Kennedy 2012)

$$
\llbracket p a r t \rrbracket=\lambda x \lambda d \lambda e\left[\operatorname{part}_{\Delta}(x)(e)=d \& \operatorname{Pat}^{\prime}(x)(e)\right]
$$

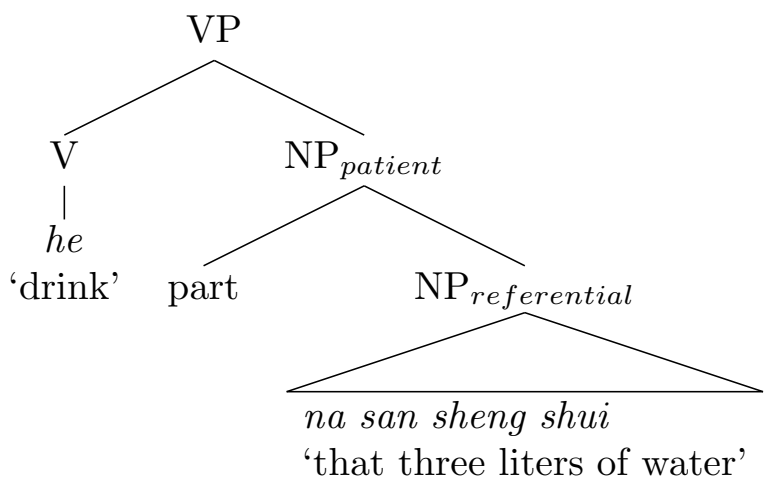

As shown in (16), syntactically speaking, first the partitive head composes with the referential NP to produce the patient NP. Because the referential entity is only partially affected, I consider it more appropriate to call this relation a patient thematic relation rather than a theme relation. And then the verb he 'drink' composes with this patient NP to build the VP. Semantically, the partitive operator takes in a referential entity or a set of referential entities and gives it a patient role in which the NP is changed in part which is measured by the degree of change of $d$. To see how the semantic derivation works, let's derive the meaning for 'drink those three liters of water' in Mandarin step-by-step as follows in (17).

$$
\begin{aligned}
& \llbracket n a \text { san sheng shui } \rrbracket=\iota x\left[\operatorname{water}^{\prime}(x) \& m^{\text {liter }}(x)=3\right] \\
& \llbracket p a r t \rrbracket(\llbracket n a \text { san sheng shui } \rrbracket) \\
& =\lambda d \lambda e\left[\operatorname { p a r t } _ { \Delta } \left(\iota x\left[\operatorname{water}^{\prime}(x) \& m^{\text {liter }}(x)=3\right)(e)=d \&\right.\right. \\
& \left.\operatorname{Pat}^{\prime}\left(\iota x\left[\operatorname{water}^{\prime}(x) \& m^{\text {liter }}(x)=3\right]\right)(e)\right] \\
& =\exists d \lambda e\left[\operatorname { p a r t } _ { \Delta } \left(\iota x\left[\operatorname{water}^{\prime}(x) \& m^{\text {liter }}(x)=3\right)(e)=d \&\right.\right. \\
& \left.\operatorname{Pat}^{\prime}\left(\iota x\left[\operatorname{water}^{\prime}(x) \& m^{\text {liter }}(x)=3\right]\right)(e)\right] \quad \text { (existential closure) } \\
& \llbracket h e \rrbracket=\lambda e\left[\operatorname{drink}^{\prime}(e)\right] \\
& \text { 【he na san sheng shui } \\
& =\exists d \lambda e\left[\operatorname { d r i n k } ^ { \prime } ( e ) \& \operatorname { p a r t } _ { \Delta } \left(\iota x\left[\operatorname{water}^{\prime}(x) \& m^{\text {liter }}(x)=3\right)(e)=d \&\right.\right. \\
& \left.\operatorname{Pat}^{\prime}\left(\iota x\left[\operatorname{water}^{\prime}(x) \& m^{\text {liter }}(x)=3\right]\right)(e)\right] \quad \text { (event identification) }
\end{aligned}
$$

As shown in (17), na san sheng shui 'those three liters of water' denotes a definite entity of water which measures to three liters in amount. Then the partitive head combines with this referential entity and gives it a partitive patient reading such that it describes that a part of this entity, which measures to $d$, participates in an event as its patient. Finally, through event identification (cf. Kratzer 1996), the verb 'drink' composes with this patient NP and gives rise to an event description of a drinking event which involves a part of the referential entity as its patient. Because of this partitive patient head, we can derive the incompletive reading semantically.

In the case of indefinite plurals, which denotes unspecific referential entities as a set of atoms, the semantic composition works exactly the same except that each referential entity within the set must enter into this partial thematic relationship with the verb separately. In other words, each of the referential entities is partially affected by the verb and the event description of the verb must apply to each of referential entities. 
4.2. SEMANTIC COMPOSITION OF THE NON-REFERENTIAL NP. When the direct NP does not have a referential reading, however, they are used quantificationally and serve as event measurements instead. In other words, the direct object NP denotes the amount of stuff that is involved in the event rather than some specific referential entities. In terms of the syntax-semantics interface for the quantificational reading, following the syntactic structure for measurement readings proposed for numeral-classifier phrases by X. Li (2013), I propose the structure in (19) and argue that sheng 'liter' in this construction has a shifted event measurement function as shown in (18), that measures how many liters of substance denoted by a noun is incrementally changed in an event.

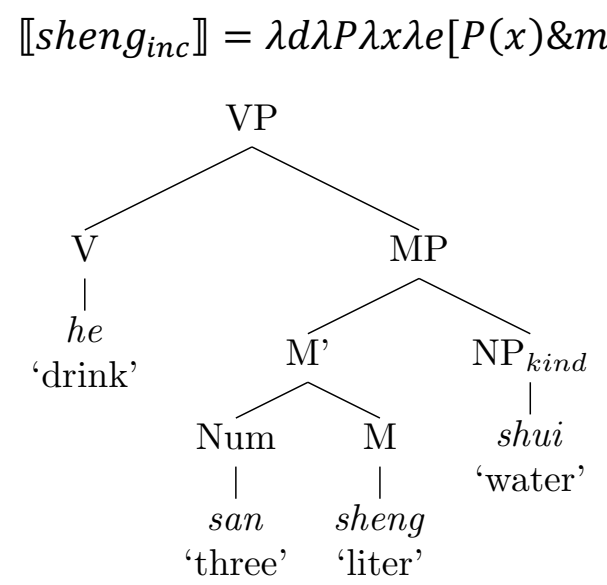

Let's look at the semantic composition of 'drink three liters of water' in Mandarin and see why this predicate can only have a completive and event homomorphic reading.

$$
\begin{aligned}
& \llbracket \text { san sheng } \rrbracket=\llbracket \text { sheng }_{\text {inc }} \rrbracket(\llbracket \text { san } \rrbracket) \\
& =\lambda d \lambda P \lambda x \lambda e\left[P(x) \& m_{\Delta}^{\text {liter }}(x)(e)=d\right](3) \\
& =\lambda P \lambda x \lambda e\left[P(x) \& m_{\Delta}^{\text {liter }}(x)(e)=3\right] \\
& \llbracket \text { san sheng shui } \rrbracket=\llbracket \text { san sheng } \rrbracket(\llbracket \text { shui } \rrbracket) \\
& =\lambda x \lambda e\left[\operatorname{water}^{\prime}(x) \& m_{\Delta}^{\text {liter }}(x)(e)=3\right] \\
& =\exists x \lambda e\left[\text { water }^{\prime}(x) \& m_{\Delta}^{\text {liter }}(x)(e)=3\right] \text { (existential closure) } \\
& \llbracket h e \rrbracket=\lambda e\left[\operatorname{drink}^{\prime}(e)\right] \\
& \text { 【he san sheng shui } \\
& =\exists x \lambda e\left[\operatorname{drink}^{\prime}(e) \& \text { water }^{\prime}(x) \& m_{\Delta}^{\text {liter }}(x)(e)=3\right] \quad \text { (event identification) }
\end{aligned}
$$

As shown in (20), the measure word sheng 'liter' has a shifted event measurement function reading that measures how much of a substance denoted by a noun is incrementally changed in an event. The measure word sheng 'liter' first takes in the degree argument san 'three' and then the noun shui 'water' to give rise to an event description that involves three liters of water. Through event identification, this event description composes with the verb he 'drink' to create a new event description which describes a drinking event involving three liters of water incrementally changed. Because the three liters of water is entirely involved in the event, the predicate can only have a completive reading.

4.3. SUMMARY AND COMPARISON WITH PREVIOUS ANALYSES. To summarize, the completive vs. incompletive reading dichotomy ultimately boils down to how the NP is interpreted: only when the NP is referential, can a part represent the whole atomic reference (cf. Rothstein 2009). And in a patient thematic relation, affecting a part stands for affecting the whole. Depending on the 
classifier or measure word, a numeral classifier phrase in Mandarin can be interpreted either referentially or quantificationally or both, and these two types of readings are different syntactically and semantically (cf. Rothstein 2010; X. Li 2013). Whereas in the referential reading, each referential entity is atomic which means that it has a boundary and is distinguishable from other referential entities; in the quantificational reading, none of the abstract measurement units is distinguishable from each other. For example, in 'three apples' and 'three bowls of water', each apple and each bowl can be distinguishable from another apple and another bowl, while in 'three liters of water', each liter of water is not distinguishable from another liter of water. Precisely because referential entities are individuated, a sub-part of a referential entity can uniquely refer back to that referential entity, whereas a sub-part of a quantificational amount cannot. Therefore, 'eat three apples' can be true in case that each of the three apples is partially eaten, whereas 'drink three liters of water' cannot be true with a incompletive reading because the three liters of water is not referring to three separate entities of one liter of water that can be partly consumed.

In comparison with previous analyses, my analysis brings a previously neglected factor, the referentiality of the noun phrase into the discussion of mereological analyses of telicity in event semantics. The Mandarin data I have presented show that referentiality holds the key to understanding why and when a incompletive reading is possible for a consumption verb with a bounded direct object. More specifically, when compared with Singh's (1991, 1998) analysis of the Hindi data, my analysis argues that there is only one partial thematic relation between the verb and the direct object that only the referential NP can enter into, instead of stipulating two different thematic relations in the mass and count domain. The completive reading is explained as following naturally from the quantificational reading of the NP, which serves only as an event measurement but does not enter into the partial thematic relation.

5. Conclusion. This paper investigates the patterns of incompletive readings for consumption verbs in Mandarin to shed light on the semantic composition of telic predicates in Mandarin. In this paper, I argue that referentiality plays a key role in determining when it is possible to assert that the direct object is only partially consumed when the direct object is quantized. Through investigating different combinations of indefinite and definite numeral-classifiers phrases, I find that the incompletive reading is felicitous when the classifier or the measure word is individuating for the indefinite NPs and always possible for the definite NPs. What is in common between these two types is that both can be referential, suggesting that referentiality rather than the mass/count distinction is responsible for the completion entailment patterns in Mandarin.

This paper contributes to event semantics by discussing extensively the referentiality of NP, a factor which is previously seldom discussed in the literature of event semantics. My paper opens up a new direction for investigating the mereological analyses of telicity and can be extended to investigation in other languages with different typologies of noun phrase structures.

\section{References}

Bach, Emmon. 1986. The algebra of events. Linguistics and Philosophy 9 (1): 5-16. Chierchia, Gennaro. 1998. Reference to kinds across language. Natural Language Semantics 6 (4): 339-405. http://link.springer.com/article/10.1023/A:1008324218506.

Dowty, David R. 1979. Word Meaning and Montague Grammar: The Semantics of Verbs and Times in Generative Semantics and in Montague's PTQ. Vol. 7. Springer.

Kennedy, Chris. 2012. The composition of incremental change. In Telicity, Change, State: A Cross-Categorical View of Event Structure, edited by Violeta Demonte and Louise 
McNally. Oxford: Oxford University Press.

Koenig, Jean-Pierre, and Lian-Cheng Chief. 2007. Scalarity and state-changes in Mandarin (and other languages). Empirical Issues in Syntax and Semantics 7: 241-62.

Kratzer, Angelika. 1996. Severing the external argument from its verb. In Phrase Structure and the Lexicon, 109-137. Springer.

Krifka, Manfred. 1989. Nominal reference, temporal constitution and quantification in event semantics. Semantics and Contextual Expression 75: 115.

Krifka, Manfred. 1998. The origins of telicity. Events and Grammar 197: 235.

Landman, Fred. 1989a. Groups, I. Linguistics and Philosophy 12 (5): 559-605. https://doi.org/10.1007/BF00627774.

Landman, Fred. 1989b. Groups, II. Linguistics and Philosophy 12 (6): 723-44. http://dx.doi.org/10.1007/BF00632603.

Li, Charles N., and Sandra Annear Thompson. 1989. Mandarin Chinese: A Functional Reference Grammar. University of California Press.

Li, XuPing. 2013. Numeral Classifiers in Chinese: The Syntax-Semantics Interface. Walter de Gruyter.

Link, Godehard. 1983. The logical analysis of plurals and mass terms: A lattice-theoretic approach.

Paul, Waltraud. 2002. Sentence-internal topics in Mandarin Chinese: the case of object preposing. Language and Linguistics 3 (4): 695-714.

Rothstein, Susan. 2008. Structuring Events: A Study in the Semantics of Aspect. John Wiley \& Sons.

Rothstein, Susan. 2009. Towards a grammar of counting and measuring. In Workshop on Nominal and Verbal Plurality, Paris, France. http://www.umr7023.cnrs.fr/sites/sfl/IMG/pdf/plNV09rothstein.pdf.

Rothstein, Susan. 2010. Counting, measuring and the semantics of classifiers. Baltic International Yearbook of Cognition, Logic and Communication 6 (1). https://doi.org/10.4148/biyclc.v6i0.1582.

Singh, Mona. 1991. The perfective paradox: Or how to eat your cake and have it too. Annual Meeting of the Berkeley Linguistics Society 17 (1): 469-79. https://doi.org/10.3765/bls.v17i0.1639.

Singh, Mona. 1998. On the semantics of the perfective aspect. Natural Language Semantics 6 (2): 171-199. http://link.springer.com/article/10.1023/A:1008208311200.

Smith, Carlota S. 1997. The Parameter of Aspect. Springer.

Soh, Hooi Ling, and Jenny Yi-Chun Kuo. 2005. Perfective aspect and accomplishment situations in Mandarin Chinese. In Perspectives on Aspect, 199-216. Springer.

Vendler, Zeno. 1957. Verbs and Times. The Philosophical Review 66 (2): 143-60. https://doi.org/10.2307/2182371. 